\title{
Comparison of osteoporotic intertrochanteric fracture fixation using a proximal femoral nail with a helical blade and lag screw type proximal femoral nail
}

\author{
Woong Chae $\mathrm{Na}^{1}$, Chae Won Lim², Sang Hong Lee \\ ${ }^{1}$ Department of Orthopedic Surgery, Gwangju Suwan Hospital, ${ }^{2}$ Department of Orthopedic Surgery, Chosun University Hospital, Gwangju, \\ Korea
}

Received April 17, 2018

Revised May 16, 2018

Accepted May 16, 2018

Corresponding author

Sang Hong Lee

Department of Orthopedic Surgery,

Chosun University Hospital, 365

Pilmun-daero, Dong-gu, Gwangju

61453, Korea

Tel: +82-62-220-3147

Fax: +82-62-226-3379

E-mail: shalee@chosun.ac.kr

ORCID:

https://orcid.org/0000-0002-2258-1147

\begin{abstract}
The aim of the study was to compare clinical and radiological results between the helical blade lag screw (proximal femoral nail antirotation II [PFNA II]) and the traditional lag screw (Zimmer Natural Nail [ZNN]) in the operative treatment of osteoporotic femur intertrochanteric fractures. We selected 182 patients who could be observed for at least 1 year from among 352 patients who received surgical treatment for osteoporotic isolated femur intertrochanteric fractures between January 2013 and December 2016. The PFNA II was applied in 110 cases, and the ZNN in 72 cases. We evaluated operation time, bleeding amount, quality of reduction, tip apex distance, bone union time, sliding distance, and lag screw position. The mean operation times and bleeding volumes were respectively 38 minutes and $224 \mathrm{~mL}$ for PFNA II, and 42 minutes and $234 \mathrm{~mL}$ for ZNN. The quality of reduction was good, acceptable, and poor in $71 \%, 25 \%$, and $4 \%$ for PFNA II, and $68 \%, 31 \%$, and $1 \%$ for ZNN, respectively. The mean tip apex distances, bone union times, and sliding distances were respectively 21.1 and $20.7 \mathrm{~mm}, 12.4$ and 12.9 weeks, and 4.2 and $3.9 \mathrm{~mm}$. The lag screw position was acceptable and poor in $95 \%$ and $5 \%$ for PFNA II, and $97 \%$ and $3 \%$ for ZNN, respectively. The design of the lag screw did not influence the surgical outcome in the osteoporotic isolated femur intertrochanteric fractures. Therefore, choice of the proximal femoral nail can safely be made according to surgeon preference.
\end{abstract}

Keywords: Femur; Intertrochanteric fracture; Proximal femur nail; Proximal femoral nail antirotation; Zimmer Natural Nail

\section{INTRODUCTION}

Intertrochanteric fracture is one of the most common pelvic injuries in the elderly population, with a prevalence 26.8 persons per 100,000 population (16.9 males and 36.8 females) [1]. The fracture occurs from high-energy impact in the younger population but is commonly derived from simple low-energy trauma such as in slip down in patients with underlying osteoporosis. The principle of treating such injury is performing prompt operation for early ambulation and rehabilitation of the patient [2-4]. For fracture fixation, historically, two instruments are used, the sliding hip screw and proximal intramedullary nail (proximal femoral nail) [5,6]. While both instruments have been shown to have excellent outcomes, a trend

This is an Open Access article distributed under the terms of the Creative Commons Attribution Non-Commercial License (http://creativecommons.org/licenses/by-nc/4.0) which permits unrestricted noncommercial use, distribution, and reproduction in any medium, provided the original work is properly cited. Copyright $@$ Medical Biological Science and Engineering. 
toward using the proximal femoral nail has been observed in the modern era owing to its ease of application, shorter surgical time, and superior biomechanics [7-11]. As the prevalence of intertrochanteric fracture is high, numerous innovations have been made to improve the outcome by modifying the instrument design. One of the greatest changes occurred in the lag screw design, the portion of the proximal nail that is used to fixate the femoral head portion. Currently, two types of lag screw is commonly being used, one having a helical blade (HB) design and the other having a traditional lag screw (TLS) design. Both were designed so that the implant may have better purchase to the cancellous femoral. Although the $\mathrm{HB}$ design has been shown to have superior outcome in biomechanics study, controversies exist in clinical setting [12-14]. To our knowledge, only a few studies have compared the two designs, of which most are reports of only a few cases. Therefore, in this study, we compared the clinical results of the intertrochanteric fracture fixation using the HB and TLS designs. Herein, we are report the result along with a literature review.

\section{MATERIALS AND METHODS}

From January 2013 to December 2016, 412 patients visited Chosun University Hospital and were diagnosed as having intertrochanteric fracture. The inclusion criterion for the present study was patients with only isolated intertrochanteric fractures that occurred from low-energy trauma. Using this criterion, 352 patients were retrieved from our database. Of these patients, 18 were treated with a sliding hip screw, and those who underwent intertrochanteric fracture fixation using a proximal femoral nail constitute the basis of our study (Fig. 1). The patients' mean age was 80.47 years (range, 65 to 98 years). The patients included 62 men and 120 women. In all the patients, dual energy X-ray absorptiometry was performed for measurement of bone mineral density and the diagnosis of osteoporosis was confirmed. Simple pelvic anteroposterior radiography and computed tomography were used to classify the fractures according to $\mathrm{AO}$ classification. Of these patients, 110 had operation using the HB design (proximal femoral nail antirotation II [PFNA II]; Synthes, Paoli, Switzerland); and 72, using the TLS design (Zimmer Natural Nail [ZNN]; Zimmer, Warsaw, IN, USA).

The demographics of the two groups are listed in Table 1. All the operations were performed by two consulting surgeons. The choice of implant was made according to the preference of the surgeon and the availability of the implant at the time of surgery. In all the cases, the operation was performed in the supine position on a regular operation table, without a fracture table. By using hospital records, the operation time, total bleeding volume, and transfusion volume were recorded. On the postoperative radiograph, the quality of reduction and appropriateness of the lag screw position were assessed by two orthopedic surgeons. For the reduction quality, classification by Fogagnolo and colleagues [15] were used, and for lag screw position, the Cleveland index and tip apex distance were used [16,17]. In addition, protrusion of the lag screw at the lateral femoral cortex was assessed by mea-

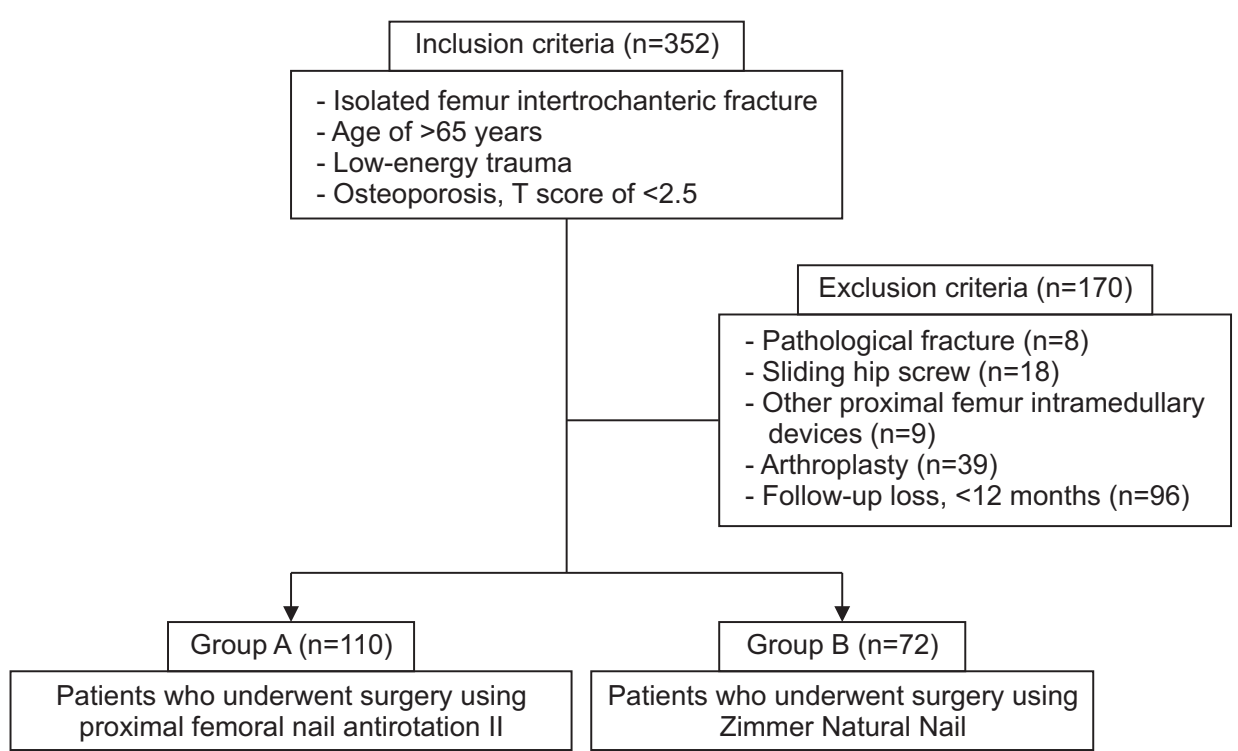

Fig. 1. Patient enrolment flow diagram. 
Table 1. Demographic data of the patients

\begin{tabular}{|c|c|c|c|}
\hline Variable & Group $A(n=110)$ & Group B $(n=72)$ & p-value \\
\hline Age (y) & 80.8 (65 to 94$)$ & 79.2 (65 to 98) & 0.78 \\
\hline Sex & & & 0.81 \\
\hline Male & 34 & 28 & \\
\hline Female & 76 & 44 & \\
\hline Bone mineral density ( $\mathrm{T}$-score) & $-3.34(-2.5$ to -6.4$)$ & $-3.48(-2.5$ to -5.8$)$ & 0.64 \\
\hline Neck shaft angle (degrees) & 125.8 & 126.4 & 0.99 \\
\hline AO type & & & 0.42 \\
\hline A1 & 37 & 23 & \\
\hline $\mathrm{A} 2$ & 51 & 35 & \\
\hline A3 & 22 & 14 & \\
\hline Follow-up period (mo) & 19 (12 to 48$)$ & 21.8 (12 to 34$)$ & 0.58 \\
\hline ASA class & & & 0.35 \\
\hline I & 26 & 14 & \\
\hline$\|$ & 49 & 29 & \\
\hline III & 35 & 29 & \\
\hline IV & 0 & 0 & \\
\hline
\end{tabular}

Values are presented as median (range) or number only. Group A: proximal femoral nail antirotation, helical blade design. Group B: Zimmer Natural Nail, traditional lag screw design. ASA: American Society of Anesthesiologists.

suring the distance from the lateral femoral cortex to the end of the lag screw head (Fig. 2). The patients were followed up for a mean of 1.6 years from surgery, until full bone healing or reoperation for variable reasons. Mean bone healing time was measured, and any complications that occurred during the follow-up period were recorded, including implant failure, nonunion, and infection. The statistical analysis was performed using the IBM SPSS ver. 20.0 statistical software (IBM Co., Armonk, NY, USA). Each variable was recorded as mean and standard deviation. The Student's t-test was performed to compare the continuous variables of the two groups, while the chi-square test was performed for nominal variables. All statistical analyses were conducted with an alpha value of 0.05 , where $\mathrm{p}$-values of $<0.05$ were considered statistically significant.

\section{RESULTS}

The mean time to operation was 3.4 days (range, 0 to 14 days) from the time of injury (3.4 and 3.5 days for the $\mathrm{HB}$ and TLS groups, respectively; $\mathrm{p}=0.91$ ). The operation time was slightly less in the HB group but did not show statistical significance. No significant differences in total bleeding volume and transfusion were found between the two groups. The quality of reduction was good, acceptable, and poor in $71 \%, 25 \%$, and $4 \%$ for the $\mathrm{HB}$ group, and $68 \%, 31 \%$, and $1 \%$ for

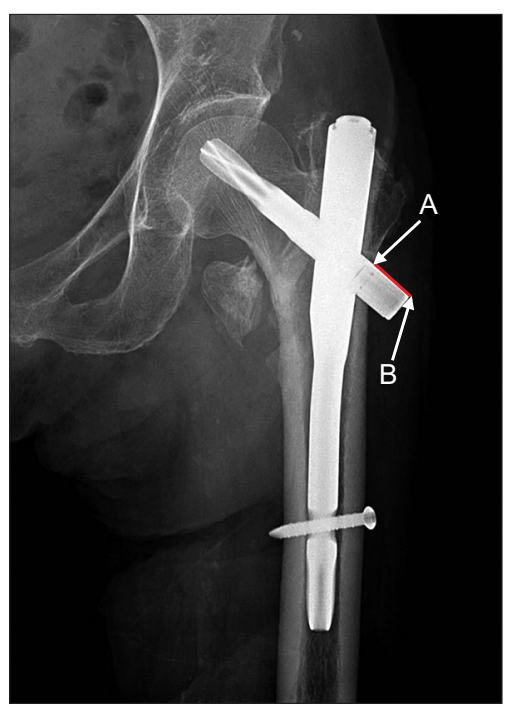

Fig. 2. Protrusion distance $(A-B)$ of the lag screw. It was assessed by measuring the distance from the lateral femoral cortex $(A)$ to the end of the lag screw head $(B)$. The sliding distance of the proximal fragment was defined as the difference in the distance $(A-B)$ before and after surgery.

the TLS group. No significant difference was found between the two groups when the quality of reduction was subdivided into Evans classification (stable vs. unstable fracture). In addition, no significant difference was found in terms of lag screw position in the two groups (Table 2). In the follow-up, lag screw cutout, backout, and other failures were observed in 1 , 11 , and 5 cases in the HB group, and 1, 10, and 3 in the TLS 
Table 2. Comparison of postoperative results

\begin{tabular}{|c|c|c|c|}
\hline Variable & Group A (n=110) & Group B $(n=72)$ & $p$-value \\
\hline Time from injury to operation (d) & 3.4 & 3.5 & 0.91 \\
\hline Operation time (min) & $38.8 \pm 15.1$ (27 to 59$)$ & $42.5 \pm 14.3$ (35 to 51$)$ & 0.51 \\
\hline Bleeding $(\mathrm{mL})$ & $224.7 \pm 151.2(50$ to 700$)$ & $234.8 \pm 137.9$ (50 to 650$)$ & 0.94 \\
\hline Transfusion $^{a}$ & 3 & 1 & 0.88 \\
\hline Quality of reduction & & & 0.43 \\
\hline Good & 78 & 49 & \\
\hline Acceptable & 28 & 22 & \\
\hline Poor & 4 & 1 & \\
\hline Tip apex ditance $(\mathrm{mm})$ & $21.1 \pm 3.4(14$ to 29$)$ & $20.7 \pm 2.6$ (16 to 33$)$ & 0.35 \\
\hline Bone union time (wk) & $12.4(10$ to 16$)$ & $12.9(11$ to 14$)$ & 0.72 \\
\hline Sliding distance of the proximal fragment & $4.2 \pm 1.4(1.2$ to 9.7$)$ & $3.9 \pm 1.3(2.5$ to 19.2$)$ & 0.09 \\
\hline Lag screw position ${ }^{\mathrm{b}}$ & & & 0.86 \\
\hline Acceptable & 104 & 70 & \\
\hline Poor & 6 & 2 & \\
\hline
\end{tabular}

Values are presented as mean \pm standard deviation (range) or number only. Group A: proximal femoral nail antirotation, helical blade design. Group B: Zimmer Natural Nail, traditional lag screw design. ${ }^{\text {TT }}$ The number of patients who received transfusion. ${ }^{b}$ Acceptable was defined as Cleveland zones 5, 6, 8, and 9; poor, as zones 1, 2, 3, 4, and 7 .

group, respectively. While a trend toward more lag screw failure was observed in the TLS group, this did not reach statistical significance. Nonunion occurred in 2 cases overall, with no significant difference between the two groups.

\section{DISCUSSION}

The results of the present study indicate that while a trend toward more operation time and lag screw cutout was observed in the TLS, the results of the two proximal nail types were comparable [18]. The proximal femoral nail has been recognized as a treatment of choice for intertrochanteric fracture owing to its short operation time and excellent biomechanical design, which enables immediate rehabilitation of the patient after surgery [19]. The traditional design of the proximal femoral nail has a lag screw to fixate the femoral head. While the result has been optimal, the number of potential complications has been reported, which includes screw cutout, loosening, Z-effect, and lateral thigh pain at the insertion point of the lag screw [20-23]. To minimize these potential complications, a newer lag screw design has been developed by several industrial corporations. ZNN was designed so that the lag screw is slightly larger than the previous design to enable more bone purchase during the fixation. On the other hand, PFNA uses the HB design, which, instead of inserting a threaded screw, uses blow to directly wedge the HB into the cancellous portion of the femoral head. Numer- ous biomechanical studies have simulated the effect of the two lag screw types and concluded that the HB is superior to the TLS in terms of resisting rotation and translation displacement [24]. However, the clinical studies suggest otherwise. A study by Kim et al. [25] compared the two types and reported no significant superiority of one type of lag screw. The study compared PFNA II (HB) and Gamma 3 (TLS), and reported complications in $4 \mathrm{HB}$ cases and 3 TLS cases. Another study by Kim and Shon [18] reviewed the results in 40 patients who had intertrochanteric fracture fixation using the two designs and reported similar results.

The study has been replicated by several different surgical groups, which showed consistent results that the outcomes of the two designs are comparable. Theoretically, the HB design should provide better stability because the cancellous bone is preserved [12]. As the biomechanical study demonstrated, we also agree that $\mathrm{HB}$ may be superior in the laboratory setting. However, in real practice, the stability of the fixation is attributed by multiple factors such as the quality of the fixation, adequacy of the screw placement, patient weight, and bone quality. As the previous clinical study included only a small number of patients for assessment, we decided to perform the study with a large study cohort to minimize the effect of the confounding factors. Nonetheless, our study shows comparable results, indicating that the design of the lag screw does not influence the surgical outcome.

We acknowledge the limitations of the present study. 
The study had a retrospective design, and the choice of the implant was not selected randomly. Nevertheless, to our knowledge, this is the largest series to compare two lag screw designs for intertrochanteric fracture fixation in the clinical setting. We believe our study provides sufficient evidence to confirm that using the contemporary proximal femoral nail will result in optimal outcome regardless of lag screw design. Therefore, choice of the proximal femoral nail can safely be made according to surgeon preference.

\section{ACKNOWLEDGEMENTS}

This work was supported by a grant from the Clinical Medicine Research Institute of the Chosun University Hospital (2015).

\section{CONFLICT OF INTEREST}

No potential conflict of interest relevant to this article was reported.

\section{REFERENCES}

1. Yoon BH, Lee YK, Kim SC, Kim SH, Ha YC, Koo KH. Epidemiology of proximal femoral fractures in South Korea. Arch Osteoporos 2013;8:157.

2. Hornby R, Evans JG, Vardon V. Operative or conservative treatment for trochanteric fractures of the femur. A randomised epidemiological trial in elderly patients. J Bone Joint Surg $\mathrm{Br}$ 1989;71:619-23.

3. Kyle RF, Cabanela ME, Russell TA, Swiontkowski MF, Winquist RA, Zuckerman JD, et al. Fractures of the proximal part of the femur. Instr Course Lect 1995;44:227-53.

4. Siegmeth AW, Gurusamy K, Parker MJ. Delay to surgery prolongs hospital stay in patients with fractures of the proximal femur. J Bone Joint Surg Br 2005;87:1123-6.

5. Utrilla AL, Reig JS, Muñoz FM, Tufanisco CB. Trochanteric gamma nail and compression hip screw for trochanteric fractures: a randomized, prospective, comparative study in 210 elderly patients with a new design of the gamma nail. J Orthop Trauma 2005;19:229-33.

6. Aune AK, Ekeland A, Odegaard B, Grøgaard B, Alho A. Gamma nail vs compression screw for trochanteric femoral fractures. 15 reoperations in a prospective, randomized study of 378 patients. Acta Orthop Scand 1994;65:127-30.

7. Huang X, Leung F, Xiang Z, Tan PY, Yang J, Wei DQ, et al. Proximal femoral nail versus dynamic hip screw fixation for trochanteric fractures: a meta-analysis of randomized con- trolled trials. ScientificWorldJournal 2013;2013:805805.

8. Carulli C, Piacentini F, Paoli T, Civinini R, Innocenti M. A comparison of two fixation methods for femoral trochanteric fractures: a new generation intramedullary system vs sliding hip screw. Clin Cases Miner Bone Metab 2017;14:40-7.

9. Parker MJ. Trochanteric hip fractures. Fixation failure commoner with femoral medialization, a comparison of 101 cases. Acta Orthop Scand 1996;67:329-32.

10. Pajarinen J, Lindahl J, Savolainen V, Michelsson O, Hirvensalo E. Femoral shaft medialisation and neck-shaft angle in unstable pertrochanteric femoral fractures. Int Orthop 2004;28:347-53.

11. Kokoroghiannis C, Aktselis I, Deligeorgis A, Fragkomichalos E, Papadimas D, Pappadas I. Evolving concepts of stability and intramedullary fixation of intertrochanteric fractures--a review. Injury 2012;43:686-93.

12. Mereddy P, Kamath S, Ramakrishnan M, Malik H, Donnachie $\mathrm{N}$. The AO/ASIF proximal femoral nail antirotation (PFNA): a new design for the treatment of unstable proximal femoral fractures. Injury 2009;40:428-32.

13. Strauss E, Frank J, Lee J, Kummer FJ, Tejwani N. Helical blade versus sliding hip screw for treatment of unstable intertrochanteric hip fractures: a biomechanical evaluation. Injury 2006;37:984-9.

14. Ito K, Hungerbuhler R, Wahl D, Grass R. Improved intramedullary nail interlocking in osteoporotic bone. J Orthop Trauma 2001;15:192-6.

15. Fogagnolo F, Kfuri M Jr, Paccola CA. Intramedullary fixation of pertrochanteric hip fractures with the short AO-ASIF proximal femoral nail. Arch Orthop Trauma Surg 2004;124:31-7.

16. Cleveland M, Bosworth DM, Thompson FR, Wilson HJ Jr, Ishizuka T. A ten-year analysis of intertrochanteric fractures of the femur. J Bone Joint Surg Am 1959;41-A:1399-408.

17. Baumgaertner MR, Curtin SL, Lindskog DM, Keggi JM. The value of the tip-apex distance in predicting failure of fixation of peritrochanteric fractures of the hip. J Bone Joint Surg Am 1995;77:1058-64.

18. Kim JH, Shon OJ. Comparative study of proximal femoral nail antirotation and zimmer natural nail for the treatment of stable intertrochanteric fractures. J Korean Fract Soc 2013;26:30513.

19. Hardy DC, Descamps PY, Krallis P, Fabeck L, Smets P, Bertens $\mathrm{CL}$, et al. Use of an intramedullary hip-screw compared with a compression hip-screw with a plate for intertrochanteric femoral fractures. A prospective, randomized study of one hundred patients. J Bone Joint Surg Am 1998;80:618-30.

20. Leung KS, So WS, Shen WY, Hui PW. Gamma nails and dynamic hip screws for peritrochanteric fractures. A randomised prospective study in elderly patients. J Bone Joint Surg Br 1992; 74:345-51.

21. Lindsey RW, Teal P, Probe RA, Rhoads D, Davenport S, Schauder K. Early experience with the gamma interlocking nail for 
peritrochanteric fractures of the proximal femur. J Trauma 1991;31:1649-58.

22. Radford PJ, Needoff M, Webb JK. A prospective randomised comparison of the dynamic hip screw and the gamma locking nail. J Bone Joint Surg Br 1993;75:789-93.

23. Sung YB, Sohn YJ, Yum JK, Chung HJ, Ahn JK, Lee SL et al. Proximal femoral nail(PFN) for intertrochanteric fracuture: long-term follow-up results. J Korean Hip Soc 2005;17:141-8.
24. Luo Q, Yuen G, Lau TW, Yeung K, Leung F. A biomechanical study comparing helical blade with screw design for sliding hip fixations of unstable intertrochanteric fractures. ScientificWorldJournal 2013;2013:351936.

25. Kim SS, Lee KY, Kim CH, Lee MJ, Wang L, Kim HJ, et al. Comparison of the dyna locking trochanteric nail, proximal femoral nail antirotation and gamma 3 nail in treatment of intertrochanteric fracture of the femur. Hip Pelvis 2013;25:211-9. 